\title{
Low Profile THz Periodic Leaky-Wave Antenna
}

\author{
Unai Beaskoetxea, Miguel Beruete, \\ Pablo Rodríguez, David Etayo and \\ Mario Sorolla \\ Electric and Electronic Engineering Department \\ Universidad Pública de Navarra (UPNA) \\ Iruña/Pamplona, Spain \\ unai.beaskoetxea@unavarra.es
}

\author{
Mokhtar Zehar, Karine Blary, \\ Abdallah Chahadih, Xiang-Lei Han \\ Tahsin Akalin \\ IEMN, \\ Lille University, \\ Lille, France \\ Tahsin.Akalin@,iemn.univ-lille1.fr
}

\begin{abstract}
In this work, a $0.566 \mathrm{THz}$ flat leaky-wave antenna, consisting of a central $\lambda_{0} / 2$ slot surrounded by straight parallel wedge corrugations, is numerically and experimentally analyzed. Simulations show a moderately high gain and no significant differences when compared with a typical square corrugation profile. Numerical comparison is also made for the designed and manufactured antennas. High transmission enhancement in the corrugated case is obtained, compared to that given by a single central slot with no grooves. This kind of antennas finds several applications in different frequency ranges, including the nowadays high-interest range of the THz.
\end{abstract}

Keywords-leaky wave antennas, THz, antennas, millimeter waves, corrugations, resonant slot

\section{INTRODUCTION}

Leaky wave antennas (LWA) [1], [2] stand out from other antenna designs as they present, despite their low profile, comparable or even higher radiation characteristics compared to larger volume antennas, as horns. Besides, the $\mathrm{THz}$ range is nowadays one of the hottest topics in electromagnetics research [3]-[6], as this part of the spectrum has not been fully exploited, giving rise to the proposal of new applications and novel devices. LWAs are thus of high interest for several applications in the THz range, as pulse- and beam-shapers[7], [8]. We can find two kinds of LWAs in the literature, those with a uniform profile, and those which follow a periodic profile. Framed in the latter group, the antenna we deal with here presents corrugations periodically distributed.

Closely associated with this kind of designs is the phenomenon of Extraordinary Optical Transmission (EOT), initially found in the optical range. It was at the beginning of the $21^{\text {st }}$ century, when it was observed that a metallic slab with sublambda perforations presented a high transmittance, in sharp contrast with what could be expected by applying directly the classical diffraction theory through a narrow aperture [9], [10]. This behavior was later observed for a central sublambda aperture surrounded by corrugations [11]. Some examples of the utility of the EOT can be found in [12][15]. The plasmonic interpretation firstly given for this phenomenon was not suitable for the microwave and millimeter range later studied [16], being replaced by a leaky wave interpretation. Based in this, several prototypes were designed and experimentally analyzed. All of them presented straight corrugations as a common feature [17], [18], with the exception of the Bull's-Eye antenna [19], whose corrugations were annular and concentric. This modification highly enhanced the antenna gain. The main characteristic of these corrugated leaky wave antennas is the capability of coupling the incident power to a leaky-wave, i.e. a surface-wave which propagates along the surface and is then in-phase reradiated to the free space by means of its corrugations, which for a single beam must excite only the $n=-1$ space harmonic [20], [21], achieving narrow beams and high directivity with a very low profile. Following this research line, two LWAs operating at $560 \mathrm{GHz}\left(\lambda_{0}=536 \mu \mathrm{m}\right)$ were designed and numerically analyzed with the full-wave 3D EM solver CST Microwave Studio ${ }^{\mathrm{TM}}$ : one with square grooves and a second one presenting a triangular corrugations profile. For the latter, manufacturing and experimental studies were carried out. The research on their radiation properties, along with the radiation and temporal properties of a THz Bull's-Eye antenna and how radiated pulses are shaped, were published in [22].

Designs are presented in Section I, followed by simulations in Section II and experimental results in Section III. Conclusions in Section IV provide a brief summary of the work.

\section{DESIGN}

Two prototypes were designed in order to compare their radiation characteristics: an antenna with square corrugations and a triangular grooves antenna. Both antennas consist of a metallic flat slab with a central slot, surrounded by periodically distributed straight grooves, approximately half the operating wavelength wide, $S_{x}=\lambda_{0} / 2$, and a slot height $S_{y}$ of about $\lambda_{0} / 9$. It couples, through its transversal resonance, the power given by a feed-waveguide at the input face to the output face. The width of the slot gives this transversal resonance, whereas its height mainly fixes the operation bandwidth. In order to obtain a near broadside radiation, the period between corrugations must be approximately equal to $\lambda_{0}$ and the distance from the slot to the first pair of opposite grooves, namely offset, $d_{l}$ and $d_{2}$, should be such as that in-phase radiation is achieved. This last parameter was obtained by means of a fine optimization, as well as the grooves' depth and width, $g_{z}$ and $g_{y}$.

Fig.1 shows both square and triangular profile antennas' cross-sectional views and a perspective view of the latter. As it can be concluded from the parameters shown in Table I, the structures only differ, apart from the geometry and dimensions of the grooves, in the distribution of the corrugations along the plate. 

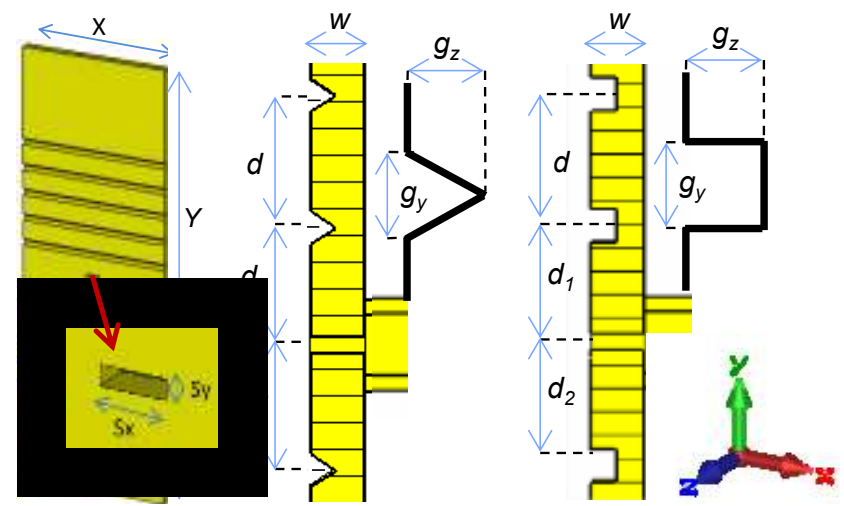

Fig. 1. Triangular and square profile antennas. Inset shows slot in detail.

TABLE I. DESIGN PARAMETERS FOR ANTENNAS

\begin{tabular}{|c|c|c|c|}
\hline Parameter & $\begin{array}{c}\text { Triangle } \\
(\boldsymbol{\mu m})\end{array}$ & $\begin{array}{c}\text { Triangle Fabr. } \\
(\boldsymbol{\mu \mathbf { m }})\end{array}$ & $\begin{array}{c}\text { Square } \\
(\boldsymbol{\mu \mathbf { m }})\end{array}$ \\
\hline Plate Width, $\mathrm{X}$ & 3000 & 2986 & 3000 \\
\hline Plate Height, $\mathrm{Y}$ & 9000 & 8938 & 9000 \\
\hline Plate Thick., $\mathrm{w}$ & 200 & 200 & 200 \\
\hline Slot Width, $\mathrm{S}_{\mathrm{x}}$ & 268 & 266 & 268 \\
\hline Slot Height, $\mathrm{S}_{\mathrm{y}}$ & 56.6 & 67.2 & 56.6 \\
\hline Period, $\mathrm{d}$ & 519 & 519 & 519 \\
\hline Offset1, $\mathrm{d}_{1}$ & 463.24 & 458 & 449.17 \\
\hline Offset2, $\mathrm{d}_{2}$ & 463.24 & 493 & 449.17 \\
\hline Gr.width, gy & 132.91 & 133 & 104.7 \\
\hline Gr. depth, gz & 94 & 95 & 74 \\
\hline
\end{tabular}

After manufacturing, a new design was also modelled with the measured dimensions (also in Table I) of the fabricated structure. This was done was as, due to fabrication tolerances, some deviations were introduced between designed and manufactured prototypes, being the offset distances and the slot height the most notable of them. As stated previously in this section, the slot height mainly fixes operation bandwidth, thus, only offset distances remained crucial.

In order to reduce computation time, magnetic and electric symmetries were used for the Y-Z and X-Z planes correspondingly, except for the fabricated design, which lacks of electric symmetry. As the fabricated structure is coated with gold, the metallic plate material considered for the simulation was gold, with electric conductivity $4.56 \times 10^{7} \mathrm{~S} / \mathrm{m}$.

This work was supported in part by the Spanish Government under Grant Consolider Engineering Metamaterials CSD200800066 and Grant TEC201128664-C02-01.

The work of U. Beaskoetxea was supported by the Public University of Navarre under the Formación de Personal Investigador 2014-1553/2013 grant The work of M. Beruete was supported by the Spanish Government under the Research Contract Program Ramón y Cajal RYC-2011-08221 and by the European Science Foundation (ESF) for the activity entitled "New Frontiers in Millimetre/Sub-Millimetre Waves Integrated Dielectric Focusing Systems." The work of M. Navarro-Cía was supported by the Imperial College Junior Research Fellowship.

\section{SimULATION RESULTS}

Spatio-temporal properties of above described structures were analyzed by means of the Transient Solver provided by CST MWS $^{\mathrm{TM}}$. As stated in Section II, the slot width determines the transversal resonance which couples incident wave, polarized in the $\mathrm{Y}$ direction, to the output interface in the form of a $\mathrm{TM}_{\mathrm{z}}$ mode surface-wave.

It was also verified that a second resonance, corresponding to the longitudinal resonance, given by the slot depth (or slab thickness), appears at around $f \sim 0.8 \mathrm{THz}$. Fig. 2 shows how both triangular and square corrugations designs barely differ in their behavior, presenting approximately a $16 \mathrm{~dB}$ gain for $f=$ $0.566 \mathrm{THz}$, i.e. a $10 \mathrm{~dB}$ enhancement compared to the flat structure.

Regarding the $-3 \mathrm{~dB}$ beamwidth $\left(\theta_{-3 \mathrm{~dB}}\right)$, the triangular grooves structure radiates a $5.8 \mathrm{deg}$ beam for the E-plane, $1 \mathrm{deg}$ narrower than the square grooves case. In the H-plane the beam is substantially wider, $\theta_{-3 \mathrm{~dB}}=26 \mathrm{deg}$. In addition, triangular corrugations present an $8.6 \mathrm{~dB}$ side lobe level, whilst the second case has a $9.7 \mathrm{~dB}$ level. When we study in detail the broadband gain obtained for these structures, Fig. 3, it can be seen that the triangular grooves case has its maximum value at $f=$ $0.566 \mathrm{THz}, 15.88 \mathrm{~dB}$, whereas the square corrugations antenna presents $16.52 \mathrm{~dB}$ at $f=0.553 \mathrm{THz}$. These minor differences are due to the higher degree of freedom when it comes to design the squared corrugations, as they are not affected by the fabrication constraints that triangular grooves do.

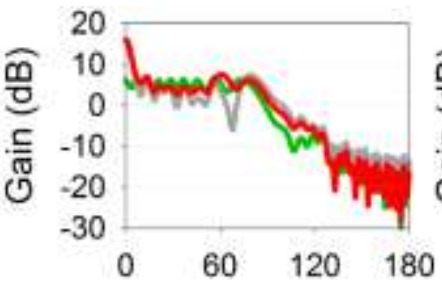

(a) Angle (deg)

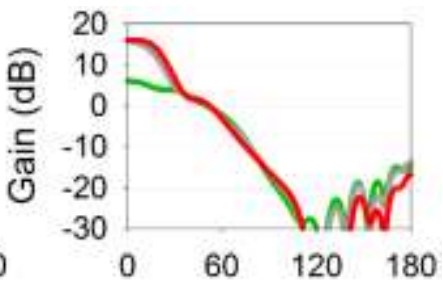

(b) Angle (deg)
Fig. 2. Radiation diagrams at $0.566 \mathrm{THz}$ in (a) E- and (b) H-planes for the triangular (red ), square (green) and no grooves (gray) structures.

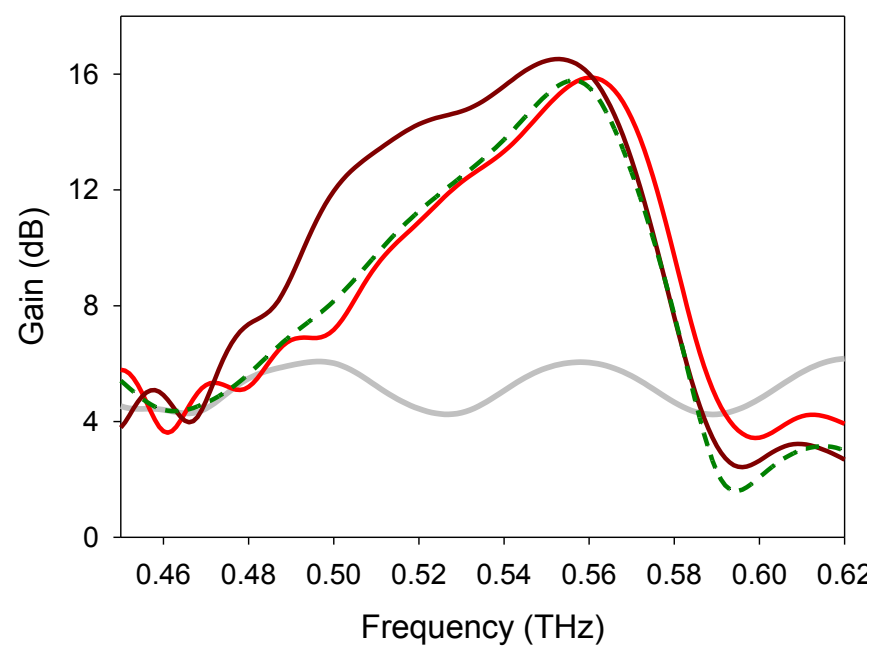

Fig. 3. Simulated broadband gain for triangular (red) and rectangular (brown) grooves structures and fabricated (green dashed) and flat structures (gray). 
The fabrication procedure fixes an angle of 70.52deg for the triangular corrugations, restricting the corrugation width. There is also another maximum at around $f=0.8 \mathrm{THz}$, slightly higher than the value given for the flat structure, corresponding to the power coupled by the longitudinal resonance, for which corrugations have little effect at that frequency. Numerical comparison between designed antenna and fabricated one displays that the latter only differs from the ideal case on a slightly reduced directivity for almost all the band and a minor frequency shift of the maximum.

\section{EXPERIMENTAL RESULTS}

In order to experimentally evaluate the fabricated antenna, Fig. 4, measurements were carried out by means of a TeraView TPS 3000 Modular Terahertz Instrument. This spectrometer excites the antenna with a Gaussian beam instead of a waveguide, thus, the characterization is more similar to a frequency selective surface measurement than to a proper antenna characterization. It was intended to quantify the transmission enhancement obtained when a flat metallic surface was patterned with periodically distributed grooves. Radiation diagrams were not evaluated, as we lacked of the adequate instruments to properly them at such frequencies.

In order to accomplish this, two measures were made. First, the corrugations were covered with copper film, so as to acquire transmission through the slot for the impinging Gaussian beam in the absence of grooves. The second test consisted in obtaining transmission when the incidence was done on the corrugated side.

As it was expected, a high increment was observed for the second case, registering an increase of almost $30 \mathrm{~dB}$, inset Fig. 5 , when periodic grooves are present. Fig. 5 shows recorded transmission normalized to the maximum of the uncovered case, localized at $f=0.566 \mathrm{THz}$. A minor second peak at $f \sim$ $0.8 \mathrm{THz}$, corresponding to the longitudinal resonance, was also obtained.

\section{CONCLUSIONS}

In this work, we have numerically proved that a $10 \mathrm{~dB}$ gain enhancement is achievable for a flat slab with a central resonant slot when a periodic grooves pattern is placed surrounding the aperture. Around $16 \mathrm{~dB}$ directivity with less than $7 \mathrm{deg}$ beamwidth and less than $10 \mathrm{~dB}$ side lobe level is observed for both analyzed triangular and square corrugations structures, barely differing in their behavior. On the other hand, an increase of approximately $30 \mathrm{~dB}$ is experimentally recorded at $0.566 \mathrm{THz}$ when a corrugated and a non-corrugated structure are illuminated with a $\mathrm{THz}$ Gaussian beam.

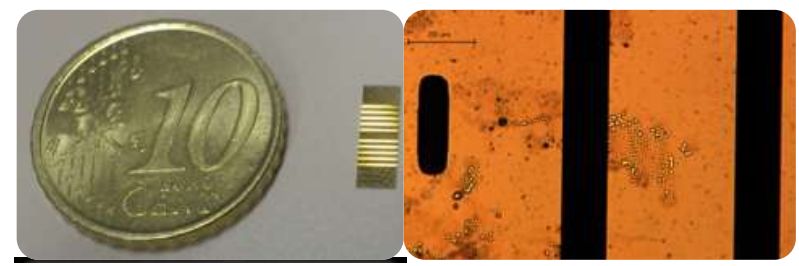

Fig. 4. Fabricated $0.566 \mathrm{THz}$ triangular corrugations LWA.

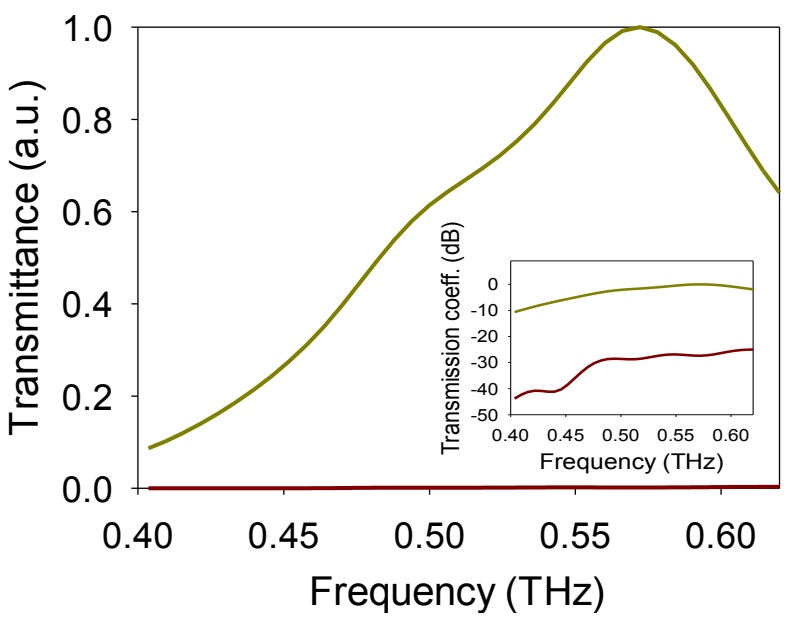

Fig. 5. Normalized transmitance for grooved (green) and covered (brown) structures. Registered transmission coefficient (inset).

It was also be observed a second maximum at approximately $f \sim 0.8 \mathrm{THz}$ corresponding to the longitudinal resonance of the slot for which corrugations, designed for $f=$ $0.566 \mathrm{THz}$, have little effect. These kind of structures are highly interesting for the $\mathrm{THz}$ range, for example, due to their capability of collimating an impinging beam, enhancing thus its gain, which may result useful for quantum cascade lasers and other novel $\mathrm{THz}$ devices.

\section{REFERENCES}

[1] A. A. Oliner, "Leaky-Wave Antennas," in Antenna Engineering Handbook, R. C. Johnson, Ed. New York: Mc Graw-Hill, 1993.

[2] L. O. Goldstone and A. A. Oliner, "Leaky-Wave Antennas I: Rectangular Waveguides," IRE Trans. Antennas Propag., vol. 7, no. 4, 1959

[3] Y.-S. Lee, "Principles of Terahertz Science and Technology," Springer, New York, 2009.

T. Akalin, "Terahertz metasurfaces: Fabrication and characterization of flat lenses and antennas," 2013 38th Int. Conf. Infrared. Millimeter, Terahertz Waves, pp. 1-3, Sep. 2013.

[5] V. Torres, V. Pacheco-Peña, P. Rodríguez-Ulibarri, M. NavarroCía, M. Beruete, M. Sorolla, and N. Engheta, "Terahertz epsilonnear-zero graded-index lens,” vol. 21, no. 7, pp. 9156-9166, 2013.

[6] N. Yu, Q. J. Wang, M. a. Kats, J. a. Fan, F. Capasso, S. P. Khanna, L. Li, a. G. Davies, and E. H. Linfield, "Terahertz plasmonics," Electron. Lett., vol. 46, no. 26, p. S52, 2010

[7] A. Agrawal and A. Nahata, "Time-domain radiative properties of a single subwavelength aperture surrounded by an exit side surface corrugation.," Opt. Express, vol. 14, no. 5, pp. 1973-1981, 2006.

A. Agrawal, H. Cao, and A. Nahata, "Excitation and scattering of surface plasmon-polaritons on structured metal films and their application to pulse shaping and enhanced transmission," New J. Phys., vol. 7, pp. 249-249, Nov. 2005.

T. W. Ebbesen, H. J. Lezec, H. F. Ghaemi, T. Thio, and P. A. Wolff, "Extraordinary optical transmission through sub-wavelength hole arrays," Nature, vol. 391, no. 6668, pp. 667-669, Feb. 1998. 
[10] M. Beruete, P. Rodriguez-Ulibarri, V. Pacheco-Peña, M. NavarroCía, and a. E. Serebryannikov, "Frozen mode from hybridized extraordinary transmission and Fabry-Perot resonances," Phys. Rev. $B$, vol. 87 , no. 20 , p. 205128 , May 2013

[11] H. J. Lezec, A. Degiron, E. Devaux, R. A. Linke, L. MartinMoreno, F. J. Garcia-Vidal, and T. W. Ebbesen, "Beaming light from a subwavelength aperture," Science., vol. 297, no. 5582, pp $820-822,2002$

[12] M. Beruete, M. Sorolla, and I. Campillo, "Left-handed extraordinary optical transmission through a photonic crystal of subwavelength hole arrays.," Opt. Express, vol. 14, pp. 5445-5455, 2006.

[13] M. Navarro-Cia, M. Beruete, I. Campillo, and M. Sorolla, "Beamforming by left-handed extraordinary transmission metamaterial bi- and plano-concave lens at millimeter-waves," IEEE Trans. Antennas Propag., vol. 59, no. 6, pp. 2141-2151, 2011.

[14] M. Navarro-Cía, M. Beruete, I. Campillo, and M. Sorolla, "Enhanced lens by $\varepsilon$ and $\mu$ near-zero metamaterial boosted by extraordinary optical transmission," Phys. Rev. B, vol. 83, no. 11, p. 115112, Mar. 2011

[15] M. Beruete, M. Navarro-Cía, and M. Sorolla, "High numerical aperture and low-loss negative refraction based on the fishnet rich anisotropy," Photonics Nanostructures - Fundam. Appl., vol. 10, no. 3, pp. 263-270, Jun. 2012

[16] M. Beruete, M. Sorolla, I. Campillo, J. S. Dolado, L. MartínMoreno, J. Bravo-Abad, and F. J. García-Vidal, "Enhanced millimeter wave transmission through quasioptical subwavelength perforated plates," IEEE Trans. Antennas Propag., vol. 53, no. 6 , pp. 1897-1903, 2005

[17] M. Beruete, I. Campillo, J. S. Dolado, J. E. Rodríguez-Seco, E. Perea, F. Falcone, and M. Sorolla, "Very Low Profile and Dielectric Loaded Feeder Antenna," IEEE Antennas Wirel. Propag. Lett., vol. 6, pp. 544-548, 2007.

[18] M. Beruete, I. Campillo, J. S. Dolado, E. Perea, F. Falcone, and M Sorolla, "Dual-band low-profile corrugated feeder antenna," IEEE Trans. Antennas Propag., vol. 54, no. 2, pp. 340-350, 2006.

[19] M. Beruete, I. Campillo, J. S. Dolado, E. Perea, F. Falcone, and M Sorolla, "Very Low-Profile 'Bull' s-Eye' Feeder Antenna," IEEE Antennas Wirel. Propag. Lett., vol. 4, no. 2, pp. 365-368, 2005.

[20] P. Burghignoli, G. Lovat, and D. R. Jackson, "Analysis and Optimization of Leaky-Wave Radiation at Broadside From a Class of 1-D Periodic Structures," IEEE Trans. Antennas Propag., vol. 54, no. 9, pp. 2593-2604, 2006

[21] S. Paulotto, P. Baccarelli, F. Frezza, and D. R. Jackson, “A microstrip periodic leaky-wave antenna optimized for broadside scanning," in IEEE Antennas and Propagation Society, AP-S International Symposium (Digest), 2007, pp. 5789-5792.

[22] M. Beruete, U. Beaskoetxea, M. Zehar, A. Agrawal, S. Liu, K. Blary, A. Chahadih, X. L. Han, M. Navarro-Cia, D. Etayo Salinas, A. Nahata, T. Akalin, M. Sorolla Ayza, M. Navarro-Cía, D. E. Salinas, and M. S. Ayza, "Terahertz Corrugated and Bull' s-Eye Antennas," IEEE Trans. Terahertz Sci. Technol., vol. 3, no. 6, pp. 740-747, 2013 